observed between daily symptoms and daily assessments of activity function items $(\mathrm{r}=0.66-0.77)$, feeling tired $(\mathrm{r}=0.66-$ 0.76), and ACQ-6 scores $(\mathrm{r}=0.58-0.68)$ at baseline and change from baseline to end of treatment. Moderate correlations were observed between symptom scores and feeling stressed $(r=0.36-0.50)$; rescue medication use $(r=0.49-0.57)$; and AQLQ(S)+12 overall and symptoms, activity limitation, and emotional domains $(\mathrm{r}=-0.41-0.62)$. Although a very weak correlation between symptom improvement and $\mathrm{FEV}_{1}$ was expected, benralizumab-treated patients had a better correlation between symptom improvement and $\mathrm{FEV}_{1}$ improvement compared with placebo ( $\mathrm{r}=-0.21$ vs. -0.13$)$, possibly because of substantial $\mathrm{FEV}_{1}$ improvement observed in benralizumabtreated patients.

Conclusions Asthma-related symptoms and improvements are associated with other important aspects of improvement in patient well-being, especially for patients uncontrolled on optimal care.

\section{P69 FUNCTIONALITY, RELIABILITY, AND PERFORMANCE OF AN ACCESSORISED PRE-FILLED SYRINGE WITH HOME- ADMINISTERED SUBCUTANEOUS BENRALIZUMAB FOR ADULT PATIENTS WITH SEVERE ASTHMA}

${ }^{1} \mathrm{AH}$ Mansur, ${ }^{2} \mathrm{GT}$ Ferguson, ${ }^{3} \mathrm{JS}$ Jacobs, ${ }^{4} \mathrm{~J}$ Hebert, ${ }^{5} \mathrm{C}$ Clawson, ${ }^{6} \mathrm{~W}$ Tao, ${ }^{6} \mathrm{Y}$ Wu ${ }^{6} \mathrm{M}$ Goldman, on behalf of the GREGALE study investigators. ${ }^{1}$ Birmingham Heartlands Hospital, Birmingham, UK; ${ }^{2}$ Pulmonary Research Institute of Southeast Michigan, Farmington Hills, MI, US: ${ }^{3}$ Allergy and Asthma Clinical Research, Walnut Creek, CA, US: ${ }^{4}$ Centre de Recherche Appliqué en Allergie de Québec, Québec, QC, Canada; ${ }^{5}$ Medlmmune LLC, Gaithersburg, MD, US; ${ }^{6}$ AstraZeneca, Gaithersburg, MD, US

\subsection{6/thoraxjnl-2017-210983.211}

Introduction and Objectives Benralizumab, a humanised antieosinophil monoclonal antibody, is in development as an addon treatment for severe, uncontrolled, eosinophilic asthma. During Phase III trials, benralizumab significantly reduced annual asthma exacerbation rates and was well-tolerated. ${ }^{1,2}$ The GREGALE study (NCT02417961) assessed patient and caregiver-reported functionality, performance, and reliability of an accessorised pre-filled syringe (APFS) used to administer benralizumab subcutaneously in an at-home setting.

Methods Patients $(n=116)$ with severe, uncontrolled asthma despite receiving medium- or high-dosage inhaled corticosteroids and long-acting $\beta_{2}$-agonists, received up to five APFSadministered subcutaneous doses (Weeks 0, 4, 8, 12, and 16) of $30 \mathrm{mg}$ benralizumab. The first three doses were administered at the study sites. The patient/caregiver administered the last two doses at home. Endpoints included the percentage of patients/caregivers who successfully administered benralizumab at home, percentage of APFS returned to study sites and evaluated as functional, percentage of APFS returned as malfunctioning to Product Complaints, efficacy (Asthma Control Questionnaire 6 [ACQ-6]), safety, and pharmacodynamics (blood eosinophil count).

Results Nearly all patients and caregivers successfully administered benralizumab with an APFS at home (Week 12: 112/114, 98\%; Week 16: 108/109, 99\%; figure 1). Two at-home administrations were unsuccessful because of patient-use error. One APFS was recorded as nonfunctional because it was not returned for evaluation. Product Complaints identified only 1 APFS malfunction of 573 dispensed. Mean ACQ-6 scores decreased from baseline through all postbaseline time points through end of treatment (baseline: mean 2.14 [standard deviation $\{$ SD $\}$ 0.81]; Week 20: mean
1.40 [SD 0.90]). Near-complete depletion of eosinophils was observed at end of treatment vs. baseline (baseline: median 250 cells $/ \mu \mathrm{L}$ [interquartile range $\{\mathrm{IQR}\} 175-430 \mathrm{cells} / \mu \mathrm{L}]$; and Week 20: median 0 cells $/ \mu \mathrm{L}$ [IQR $0-10$ cells $/ \mu \mathrm{L}])$. Incidence of adverse events leading to benralizumab discontinuation was $2.6 \%$. Most common adverse events ( $\geq 5 \%$ of patients) were nasopharyngitis, upper respiratory tract infection, headache, and sinusitis. Five patients $(4.3 \%)$ experienced transient mild or moderate injectionsite reactions.

Conclusions Most patients and caregivers successfully administered benralizumab in an at-home setting. The APFS was functional, reliable, and performed well.

Please refer to page A258 for declarations of interest in relation to abstract P69.

\section{REFERENCES}

1. Bleecker ER et al. Lancet 2016;388:2115-27.

2. FitzGerald JM et al. Lancet 2016:388:2128-41.

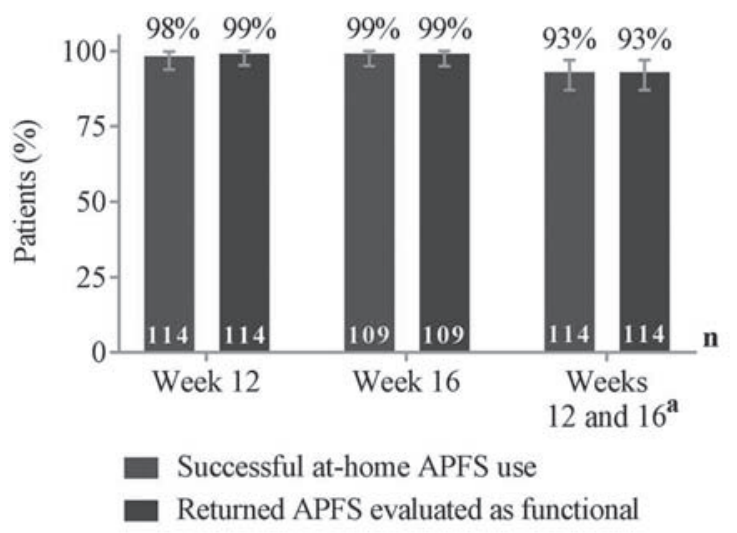

APFS, accessorized pre-filled syringes.

${ }^{a}$ Includes patients who were qualified for home-administration and were still in the study at Week 12 .

Error bars represent $95 \%$ confidence intervals calculated using the Clopper-Pearson exact method.

Abstract P69 Figure 1 Percentage of patients and caregivers who used an APFS successfully at home and returned APFS evaluated as functional.

\section{P70 RELATION BETWEEN BRONCHIAL ASTHMA AND PARASITIC (NEMATODES) INFECTION IN EGYPTIAN CHILDREN}

${ }^{1}$ YM Bakr, ${ }^{2} \mathrm{MM}$ Shahin, ${ }^{2} \mathrm{MH}$ Zidan, ${ }^{3} \mathrm{AA}$ Alfatah, ${ }^{2}$ JS Gharraf. ${ }^{1}$ Alexandria Police Hospital, Alexandria, Egypt; ${ }^{2}$ Alexandria Medicine Faculty, Alexandria, Egypt; ${ }^{3}$ Alexandria Medical High Institute, Alexandria, Egypt

\subsection{6/thoraxjnl-2017-210983.212}

Background Among the many factors influencing the prevalence of asthma in developing countries from the tropics are geo-helminthic infections.

Aims This work aims to study the relation between bronchial asthma and parasitic infestation in Egyptian children.

Patients and Methods A cross-section, analytical study design was chosen to perform this research on 100 school aged children. All children were interviewed and examined clinically and laboratory. 
Setting Alexandria Police Hospital.

Results $86 \%$ of patients with bronchial asthma lived in urban areas, while $64 \%$ of patients with parasitic infestation lived in rural areas. Statistically significantly Negative correlations were found between blood level of IgE and FEV1\% of predicted in patients with bronchial asthma as well as patients with parasitic infestation with $\mathrm{r}=-0.381,-0.325$ at $\mathrm{p}=0.006,0.021$ respectively. Inverse relationship was found between blood level of IgE and $\mathrm{FEV} 1 / \mathrm{FVC} \%$ in patients with parasitic infestation with $r=-0.358$ with statistical significant difference at $p=0.011$.

Conclusions Statistically significance higher values of $\operatorname{IgE}$ were found in patients with parasitic infestation compared to patients with bronchial asthma. It was noted that patients with combined bronchial asthma and parasitic infestation demonstrated statistically significance higher values of IgE which suggest a possible synergistic effect of two diseases.

Recommendation Improving personal and environmental hygiene and regular screening, treatment and health education for children as regard parasitic infections is recommended.

\begin{tabular}{|l|c|c|c|c|c|}
\hline & $\begin{array}{c}\text { Asthmatic } \\
(\mathbf{n}=\mathbf{4 8})\end{array}$ & $\begin{array}{c}\text { Parasitic } \\
(\mathbf{n}=\mathbf{4 7})\end{array}$ & $\begin{array}{c}\text { Combined } \\
(\mathbf{n}=\mathbf{5})\end{array}$ & KW & $\mathbf{p}$ \\
\hline IgE & & & & & \\
$\begin{array}{l}\text { Min. }- \\
\text { Max. }\end{array}$ & $100.0-490.0$ & $122.0-900.0$ & $850.0-1003.0$ & & \\
$\begin{array}{l}\text { Mean } \pm \\
\text { SD. }\end{array}$ & $\begin{array}{c}258.35 \pm 106 . \\
58\end{array}$ & $\begin{array}{c}400.79 \pm 196.7 \\
9\end{array}$ & $938.40 \pm 63.56$ & 26.302 & $<0.001$ \\
Median & 247.0 & 344.0 & 950.0 & & \\
\hline $\begin{array}{c}\text { Sig. Bet. } \\
\text { Grps. }\end{array}$ & \multicolumn{2}{|c|}{$\mathrm{p}_{1}<0.001^{*}, \mathrm{p}_{2}<0.001^{*}, \mathrm{p}_{3}<0.001^{*}$} & & \\
\hline
\end{tabular}

KW: Kruskal Wallis test, Sig. bet. grps was done using Mann Whitney test

$\mathrm{p}_{1}$ : $\mathrm{p}$ value for comparing between asthmatic and parasitic group

$\mathrm{p}_{2}$ : $\mathrm{p}$ value for comparing between asthmatic and combined group

$\mathrm{p}_{3}$ : $\mathrm{p}$ value for comparing between parasitic and combined group

*: Statistically significant at $\mathrm{p} \leq 0.05$.

Abstract P70 Figure 1 Comparison between the three groups according to IgE.

\section{P71 MEPOLIZUMAB IN ADOLESCENTS WITH SEVERE EOSINOPHILIC ASTHMA NOT ELIGIBLE FOR OMALIZUMAB: ONE CENTRE'S EXPERIENCE}

${ }^{1}$ E Weir, ${ }^{2}$ JY Paton. ${ }^{1}$ Royal Hospital for Children, Glasgow, UK; ${ }^{2}$ School of Medicine, College of Medical, Veterinary and Life Sciences, University of Glasgow, Glasgow, UK

\subsection{6/thoraxinl-2017-210983.213}

Introduction Mepolizumab is an anti-interleukin-5 monoclonal antibody shown to reduce asthma exacerbations in adults and adolescents with severe eosinophilic asthma. ${ }^{1}$ The Scottish Medicines Commission has accepted it for restricted use in adults as an add-on treatment for severe refractory eosinophilic asthma. Here we describe the use of Mepolizumab as an unlicensed medicine with local approval for use in adolescents with severe asthma.
Methods Mepolizumab was offered to adolescents with severe eosinophilic asthma not eligible for Omalizumab because of previous allergic reaction $(n=2)$ or failure to respond $(n=1)$ to Omalizumab, or excessively high $\operatorname{IgE}(n=4)$. Eosinophilic asthma was confirmed: blood eosinophil count $\geq 300$ cells $/ \mu \mathrm{L}$ or exhaled nitric oxide concentration (FeNO) $\geq 50 \mathrm{ppb}$ in the previous year. All received high-dose ICS + LABA and had low ACT scores (mean 10.4 \pm 2.88 ). Four were on daily oral steroids. Mean exacerbations requiring oral steroids in the previous year were $4.9 \pm 1.68$. Prior to commencing and before each monthly injection, pulmonary function (FeNO and forced expiratory volume in $\left.1 \mathrm{~s}\left(\mathrm{FEV}_{1}\right)\right)$, blood eosinophil count, Asthma Control Test (ACT) and Paediatric Asthma Quality of Life Questionnaire (PAQLQ) were measured. Long-term medications not adjusted. Data from clinical case notes.

Results Seven adolescents (mean age 13.9 \pm 1.9 , range 11-17 years; 5 males, 2 females) each received 4 Mepolizumab doses (100 mg sc) at monthly intervals with no serious adverse reactions. Blood eosinophil count decreased in all (mean pre-treatment $0.8 \pm 0.62 \times 10^{9}$ cells $/ \mathrm{L}, 0.1 \pm 0.06 \times 10^{9}$ cells $/ \mathrm{L}$ after 4 doses). ACT score improved in $6 / 7$ patients $(86 \%)$ (mean pretreatment $10.4 \pm 2.88,13.6 \pm 5.16$ after 4 doses). PAQLQ improved in $4 / 7$ patients $(57 \%$ ) (mean pre-treatment 3.8 $\pm 1.30,4.4 \pm 1.41$ ). We did not demonstrate improvement in $\mathrm{FEV}_{1}$. Mean FeNO was $-15 \pm 29 \mathrm{ppb}$ (figure 1). During treatment, none required hospitalisation for asthma attacks, 2/7 patients (29\%) were attack free, 5/7 patients (71\%) had reduced attack frequency.

Conclusion In adolescents with refractory eosinophilic asthma not eligible for Omalizumab, these data suggest that Mepolizumab is well tolerated, reduces risk of exacerbations, may improve asthma control and quality of life but does not improve lung function.

\section{REFERENCE}

1. Pavord ID, et al. Mepolizumab for severe eosinophilic asthma (DREAM): a multi centre, double-blind, placebo-controlled trial. Lancet 2012;380(9842):651-9.

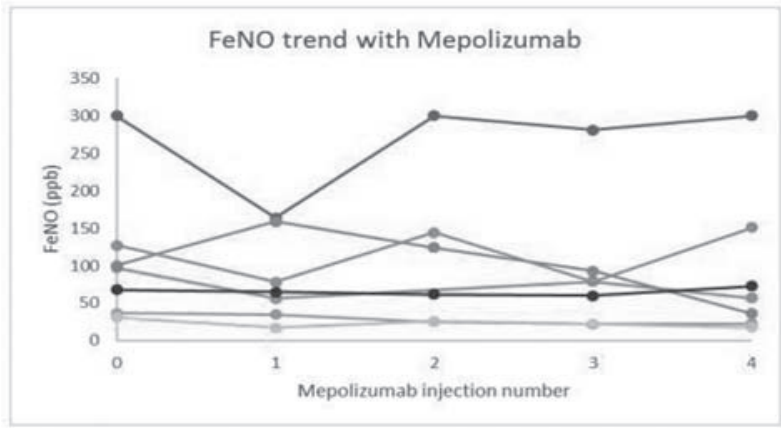

Abstract P71 Figure 1

\section{Pulmonary rehabilitation: walk this way}

\section{P72 IS THE USE OF A NOVEL HIGH FREQUENCY AIRWAY OSCILLATING DEVICE FEASIBLE FOR THE MANAGEMENT OF CHRONIC OBSTRUCTIVE PULMONARY DISEASE?}

E Daynes, TC Harvey-Dunstan, NJ Greening, SJ Singh. Centre of Exercise and Rehabilitation Sciences, Leicester Biomedical Research Centre- Respiratory, Leicester, UK

10.1136/thoraxjnl-2017-210983.214 


\section{Withdrawn: P70 Relation between bronchial asthma and} parasitic (nematodes) infection in egyptian children

Bakr YM, Shahin MM, Zidan MH, et al. P70 Relation between bronchial asthma and parasitic (nematodes) infection in egyptian children. Thorax 2017;72:A119-A120. doi:10.1136/ thoraxjnl-2017-210983.212

This abstract has been withdrawn. It was not presented at the meeting.

(c) Article author(s) (or their employer(s) unless otherwise stated in the text of the article) 2018. All rights reserved. No commercial use is permitted unless otherwise expressly granted.

Thorax 2018;73:396. doi:10.1136/thoraxjnl-2017-210983.212wthn

(D) Check for updates 